\title{
Reformation Professional academies Information literacy Education Promotion High-quality Information Military Talent Training
}

\author{
WU Yanmei ${ }^{1, a}$, PENG Zhijun ${ }^{2, b}$, WEN Xingwang ${ }^{3, c}$ \\ ${ }^{1}$ Academy of Equipment, Beijing, 101416, China \\ ${ }^{2}$ Kunming University of Science \& Technology, Kunming, 650224, China \\ ${ }^{3}$ Academy of Equipment, Beijing, 101416, China

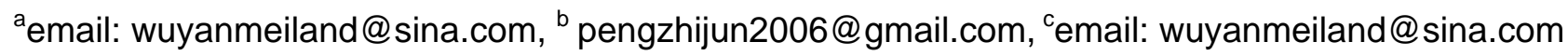

Keywords: Professional Education; Information Literacy; Culture

\begin{abstract}
Information literacy is the essential quality for the military talents, and is the concentrated expression of the comprehensive quality of military talents. In this paper, the connotation of the information literacy is explained. And the reform measures are also proposed from reforming information literacy training system, optimizing information technology teaching environment, exercising capacity for scientific research, expanding education and training channels to promote information literacy education.
\end{abstract}

\section{Introduction}

With the rapid development of science and technology, the high-tech not only led to enormous changes in the economic and social, but also to trigger the profound changes in the military theory, war form and operation manner. Information has become the dominant factor for the outcome of a war. And the contest of future war will be that of human information literacy.

In the United States Army, as an example, the military professional qualities are emphasized. They focus on training their ability of information processing, cooperative control ability and independent operational capability. The trainees are expected to have ability to distinguish useful information and useless information, important information and secondary information in the future information war, to protocol battle plan on the electronic map directly, issued combat command, assist commanders judgment and decision-making. Chilcote major general, the president of U.S. military academy, pointed out, the strategic commander in the information age should have eight abilities: acquaintance the battle situation, command high level troops, use a large amount of information, quick response to the new information and changing environment, proper implementation of command and control, good psychological and physical quality, operation a computer, as well as understanding "twenty-first century forces development and implementation " etc.. In recent years, the U.S. military academies put the "training professional officer in the information age" as the direction of education reform and the basic task and set up the course information. Their aim is not only to make students understand the common information warfare means, but also to pay more attention how to use the information to control the war [1].

Therefore, information literacy has become a required quality of new military talents, a key factor of the information combat effectiveness, and an important foundation to promote the construction of military information. As the pathway to enhance the information literacy, the professional education should strengthen efforts to train and promote the construction and training of highly qualified information technology personnel team with the times requirements.

This paper is organized as follows: section 2 is the connotation of the information literacy required by the new military talent. Section 3 presents the measures of promotion the information literacy of professional education. Section 4 is the conclusion.

\section{Connotation of Information Literacy Required by New Military Talent}

The concept of information literacy is provided by Paul. Zekaosi in 1974. He was the chairman 
of the U.S. information industry association. He defined the information literacy as "the technologies and skills to answer the questions by using information and tools". It includes three aspects: cultural literacy (knowledge), information awareness (awareness level) and information skills (technically) [2]. With the development and extensive application of the multimedia and computer network technology, the human society has entered the information society. The information literacy has been given new definition. At present, the information literacy is defined as the ability to solve the problems using information technology [3]. It includes not only the ability to use information tools and resources, but also the ability to choose, obtain and identify information, to process, handle and transmit information and the ability to create information. With the development of information technology and the information society, the original meaning of information literacy has been gradually deepened, and extended to multi-aspects, including information awareness, information knowledge, information ability, information ethics, information psychological, and information cultural [4,5]. Its core is the abilities of the information processing and information technology application.

The information literacy of the new military talent is professional quality in the military field evolved from the basic connotation of information literacy. It mainly indicates that the military personnel have proficient knowledge of information warfare and information awareness required by the information warfare as well as the basic qualities of information access, processing, use etc. in the military occupation and activities related to national security [6].

\section{- Information awareness}

Information awareness refers to the self-awareness of information need, namely the ability to feel, understand and evaluate the nature and social phenomena, behavior, to capture and determine the useful information from the information view. The information awareness of military pay more attention to military information, such as information strategic awareness, information superiority awareness, information urgency awareness, information security awareness, and awareness of lifelong learning.

\section{- Information knowledge}

Information knowledge refers to all theory, knowledge and methods related to information, including the information theoretical knowledge and IT knowledge. Information theory involves information terminology, the structure and components of information systems, and the methods and principles of the information processing as well as the social cultural characteristics. The information knowledge of military mainly includes the information theoretical knowledge and IT knowledge about operational theory, manner and combat systems.

\section{- Information capacity}

Information capacity refers to the ability to effectively use information tools and resources to obtain information, processing information, as well as the ability to make use of information. This is important to the viability of the information age. The information capacity mainly includes the capability to obtain, understand, handle, utilize and express information. Information capacity of military should have the ability to control information system based on network combat, organize information warfare and information defense besides the effective use information tools and network to obtain, processing and utilization information.

\section{- Information Ethics}

Information Ethics refers to the ethical moral sentiments in information activities, which demands solving problems with information technology lawfully, fairly and reasonably. It is the specification of regulating the relationship between the information creators, services and users. The information ethics of military is to comply with the relevant laws and regulations of the state and the army, to follow the ethical and moral standards, to enhance self-discipline and awareness of information security, to resist negative information and erroneous thinking, as well as to standardize personal information behaviors.

- Information psychology

Information psychology means the psychological process that people understand and exchange information in the cognition and transformation the world [6]. In the modern warfare, the 
information superiority formed from the news media, network technology, political influence, often leads to psychological fear, destroy opponent's psychological defense, and yield opponent's the resistance will [7]. The information psychology of military mainly reflects in the rational identification information, prevention bad information, and improvement resistance to negative information and promotion defense capabilities.

- Information culture

Information culture is the cultural pattern of information activities, which is a new type of culture with development of human society. It is the sum of the ideas, behaviors and matter created by human information activities. The information culture of the military should be the scientific and correct spiritual values as dominant support of the information cultural construction.

In short, information awareness, information knowledge, information capacity, information ethics, information psychology and information culture interact each other to constitute information literacy. Information awareness plays a leading role in the information literacy. Information knowledge and information capacity constitute the basis and core of the information literacy. Information ethics and information psychology are the guarantee of the healthy development of information literacy. Information culture is the foundation of the command information literacy.

\section{Measures of Promotion the Information Literacy of Professional Education}

Professional education is a teaching activity for the purpose of providing knowledge, ability and quality required by the position, which includes pre-job training and on-the-job training. In the vertical, the professional education involves the complete training system from the growth officer position to the high-ranking officers. In the horizontal, the professional education includes all kinds of talents training in coordination and mutual support. Information warfare demands the military must have good comprehensive quality, complex knowledge structure and the spirit of innovation and creativity [8], which is the key to transfer the information superiority into decision superiority and operational advantages. Therefore, the professional education must enhance information literacy training measures to improve information literacy of the trainee under the requirements of information military talents.

- Definition the training objects of the information literacy in the professional education

The training objects are to foster the trainee's information strategy awareness, possess comprehensive knowledge structure, master information application ability, mould noble ethics, develop good psychological quality and precipitate profound information culture in accordance with the requirements of the military information literacy .

- Reform the training contents of the information literacy in the professional education

According to the information literacy training objectives of the professional education and combining the principles of hierarchy development, the training contents should be designed scientifically. It should focus on the coordinate planning, command and control, technical support under the aim of promoting system combat ability and develop joint exercises so as to culture the trainee's tactics and technique as well as command and management.

- Construction evaluation system of the information literacy in the professional education

The appropriate system evaluation should also be developed to check the information literacy training level and effect. According to "Beijing area university information literacy standards" and combining with the training targets of information literacy in the professional education, the quantitative evaluation system of the information literacy training can be determined.

- Improvement the information teaching environment

It should be to improve the campus environment, and create information technology teaching atmosphere in accordance with the training objectives. The network combat based on the information system need rapid situational awareness, speedy command and control as well as precise fighting, which requires combatants to transform the information superiority into knowledge superiority, and thus form decision superiority and action advantages. Therefore, the campus should establish a teaching system with digitization, simulation and networking and practice information 
technology in teaching. For example, to cultivate information-based military talents through some information operation drills, such as simulation training, online training, and online exercise etc..

- Enhancement the information research capacity

It should to develop the special professional education researches in order to improve the information literacy by staring at the forefront of the information technology development, aiming at the pinnacle of the information technology development, and combining with the army and academies reality.

- Reinforcement the teachers' information literacy

Information literacy teachings call for strengthening the teachers' information literacy [9]. Firstly, it is necessary to establish a modern information education concept, and enhance teacher's information awareness. Secondly, it must improve the teaching organization and design abilities to enhance the ability of information application. Thirdly, it is obliged to strengthen the research and development of instructional technology to promote information innovation capability.

- Expansion the educational channels of the information training

It should be to expand the education channels by coordinating and cooperating with the army, universities, institutes and enterprises to develop multi-level training mechanism and to utilize various education resources.

\section{Conclusion}

Future information warfare will have characteristics of transformation the quantity and scale into quality and efficiency, and the manpower-intensive into technology-intensive, which highlights the urgency and importance of information literacy training in preparations for military struggle. Therefore, professional education must be oriented to the future information warfare demand, reform information literacy training system, optimize information technology teaching environment, exercise scientific research capacity, and expand the channels for education and training so as to promote information literacy training, raise the comprehensive quality of the trainees, culture more quality information technology talents.

\section{References}

[1] Li Huiguang. American Information Warfare and Information Construction. Beijing: Military Science Press, 2004:388.

[2] Cai Dongmei. The Penetration of Information Literacy Cultivation in the University Teaching. http://edu.lib.tsinghua.edu.cn/Electronic Journal

[3] Peng Shaodong. Discrimination of the Information Literacy and Information literacy. China Education Newspaper.2002 .10.3.

[4] Tang Yueping Tian Xin. Improvement of Information Literacy is the Key to Enhance the Combat Capability of Information System[J]. Continuing Education.2011: 50-53

[5] Sui Qian. Information Literacy of the New Military Talents [J]. PLA University of Science and Technology. 2004.52-54.

[6] Ye Xiaoyan. Information Psychological is the Internalization of Information Literacy [J]. Computer Knowledge and Technology.2010:7964-7966.

[7] Xu Hejiang Study on the Informatization Psychological under the Information Warfare [J]. Scientific and Educational.2009:285

[8] Chang Xinguo, Zhang Feng. Plan Talent Project Standing in the Forefront of New Military Revolution. Liberation Army Daily.2003.10.21.

[9] Wang Yunhui. Several Thinking about the Culture Teachers' Information Lliteracy in the Professional Educational Institutions [J]. Technology Information. 2012.12:61 